Abstract

\title{
Development of Sliced Bread with Better Nutritional Quality: Optimization of Wheat Flour Replacement with Germinated Pseudocereals for Doughs with Better Rheological Properties ${ }^{\dagger}$
}

\author{
Luz María Paucar-Menacho 1,*, Williams Esteward Castillo-Martinez 1, Wilson Daniel Simpalo Lopez ${ }^{1}$, \\ Lourdes Esquivel-Paredes ${ }^{1}$ and Cristina Villaluenga ${ }^{2}$ \\ 1 Departamento de Agroindustria y Agrónoma, Facultad de Ingeniería, Universidad Nacional del Santa, \\ Nuevo Chimbote, Ancash, Nuevo Chimbote 02712, Peru; wcastillo@uns.edu.pe (W.E.C.-M.); \\ wsimpalo@uns.edu.pe (W.D.S.L.); lesquivel@ucv.edu.pe (L.E.-P.) \\ 2 Department of Food Characterization, Quality and Safety, Institute of Food Science, Technology and \\ Nutrition (ICTAN-CSIC), 28040 Madrid, Spain; c.m.villaluenga@csic.es \\ * Correspondence: luzpaucar@uns.edu.pe \\ † Presented at the 1st International Electronic Conference on Food Science and Functional Foods, \\ 10-25 November 2020; Available online: https://foods_2020.sciforum.net/.
}

Citation: Paucar-Menacho, L.M.; Castillo-Martinez, W.E.; Lopez, W.D.S.; Esquivel-Paredes, L.; Villaluenga, C. Development of Sliced Bread with Better Nutritional Quality: Optimization of Wheat Flour Replacement with Germinated Pseudocereals for Doughs with Better Rheological Properties. Proceedings 2021, 70, 12. https://doi. org/10.3390/foods_2020-07806

Published: 10 November 2020

Publisher's Note: MDPI stays neutral with regard to jurisdictional claims in published maps and institutional affiliations.

Copyright: (C) 2020 by the authors. Licensee MDPI, Basel, Switzerland. This article is an open access article distributed under the terms and conditions of the Creative Com-mons Attribution (CC BY) license (http://creativecommons.org/licenses/by/4.0/).

\begin{abstract}
The incorporation of germinated grains in food formulation is an increasing trend, due to its superior nutritional quality and health-promoting properties as compared to their ungerminated counterparts. The aims of this study were: (1) to improve the nutritional properties of sliced bread by the replacement of wheat flour (WF) with germinated quinoa (GQF), kiwicha (GKF), and cañihua (GCF) flours; and (2) to optimize composition of flour blends using a Simplex Centroid Mixture Design (SCMD), the desired function methodology and performing the screening of rheological parameters in bread doughs (development time, stability time, resistance to extension, gelatinization temperature, and maximum gelatinization). Bioactive compounds (total phenolic compounds, TPC; gamma-aminobutyric acid, GABA) and antioxidant activity (oxygen radical absorbance capacity, ORAC) of flours from germinated grains was performed. A total of 14 flour blends formulations based on GQF (5-15\%), GCF (5-15\%), and WF (80-90\%) blends or GKF (5-15\%), GCF (5-15\%), and WF $(80-90 \%)$ were included in the SCMD to determine the optimal dough that guarantees a sliced bread with technological and sensory quality. TPC, GABA, and ORAC in flours of germinated pseudocereals ranged from 72-134 mg gallic acid equivalents/100 g, 100-217 mg/100 g, and 448-3395 mg trolox equivalents $/ 100 \mathrm{~g}$, respectively. The results indicated that the substitution levels influence the rheological properties of WF doughs (control). Highest desirability values were observed for doughs produced from the following two flour blends: $87.6 \%(\mathrm{WF}), 5 \%(\mathrm{GKF})$, and $7.4 \%$ (GCF); and $84.6 \%$ (WF), 5\% (GQF) and 10.4\% (GCF). This investigation clearly indicates that germinated pseudocereal grains could be used to produced sliced breads with higher nutritional quality and acceptable technofunctional properties.
\end{abstract}

Supplementary Materials: The following are available online at https://www.mdpi.com/25043900/70/1/12/s1.

Funding: L.M. Paucar-Menacho, acknowledges the financial support of the Proyecto ConcytecBanco Mundial, through its executing unit the Fondo Nacional de Desarrollo Científico, Tecnológico y de Innovación Tecnológica (Fondecyt). 